\title{
The association of DNA damage response and nucleotide level modulation with the antibacterial mechanism of the anti-folate drug Trimethoprim
}

\author{
Dipen P Sangurdekar', Zhigang Zhang ${ }^{3,4}$ and Arkady B Khodursky ${ }^{2,3 *}$
}

\begin{abstract}
Background: Trimethoprim is a widely prescribed antibiotic for a variety of bacterial infections. It belongs to a class of anti-metabolites - antifolates - which includes drugs used against malarial parasites and in cancer therapy. However, spread of bacterial resistance to the drug has severely hampered its clinical use and has necessitated further investigations into its mechanism of action and treatment regimen. Trimethoprim selectively starves bacterial cells for tetrahydrofolate, a vital cofactor necessary for the synthesis of several metabolites. The outcome (bacteriostatic or bactericidal) of such starvation, however, depends on the availability of folate-dependent metabolites in the growth medium. To characterize this dependency, we investigated in detail the regulatory and structural components of Escherichia coli cellular response to trimethoprim in controlled growth and supplementation conditions.

Results: We surveyed transcriptional responses to trimethoprim treatment during bacteriostatic and bactericidal conditions and analyzed associated gene sets/pathways. Concurrent starvation of all folate dependent metabolites caused growth arrest, and this was accompanied by induction of general stress and stringent responses. Three gene sets were significantly associated with the bactericidal effect of TMP in different media including LB: genes of the SOS regulon, genes of the pyrimidine nucleotide biosynthetic pathway and members of the multiple antibiotic resistance (mar) regulon controlled by the MarR repressor. However, the SOS response was identified as the only universal transcriptional signature associated with the loss of viability by direct thymine starvation or by folate stress. We also used genome-wide gene knock-out screen to uncover means of sensitization of bacteria to the drug. We observed that among a number of candidate genes and pathways, the effect of knock-outs in the deoxyribose nucleotide salvage pathway, encoded by the deoCABD operon and under the control of the DeoR repressor, was most informative.

Conclusion: Transcriptional induction of DNA damage response is an essential feature of the bactericidal effect of trimethoprim. Either the observation of the transcriptional response or DNA damage itself, or both, is made possible by thymine starvation when other folate-dependent metabolites are not limited. The effect of DNA damage by the drug takes place prior to its bactericidal effect, at the beginning of the lag stage of the treatment. Mutations in the deoxyribose nucleotide salvage pathway can affect duration of the lag as well as the rate of killing. This information can be used to postulate certain mechanistic differences between direct thymine starvation in thymidylate synthase deficient mutants and thymine starvation by anti-folate inhibitors.
\end{abstract}

\footnotetext{
* Correspondence: khodu001@umn.edu

${ }^{2}$ Department of Biochemistry, Molecular Biology and Biophysics, University of

Minnesota, 1479 Gortner Ave, Saint Paul, MN 55108, USA

Full list of author information is available at the end of the article
} 


\section{Background}

2,4,-diamino-5-(3', 4', 5'-trimethoxybenzyl)-pyrimidine (Trimethoprim, TMP) is a folate analog that inhibits the reduction of dihydrofolate to tetrahydrofolate (THF) by competitively binding the active site of the enzyme dihydrofolate reductase (DHFR) [1,2]. The drug is highly specific against bacterial and malarial enzymes [3], has a wide antibacterial spectrum and, despite emerging resistance [4-7], has been extensively used against urinary and respiratory tracts infections and against enteric pathogens and methicillin resistant S. aureus [8].

Trimethoprim treatment reduces the pool of 5,6,7,8tetrahydrofolate (THF) by inhibiting DHFR, encoded by the folA and folM genes in E. coli (Figure 1). THF is methylated during the synthesis of glycine from serine and gets converted to 5,10-methylenetetrahydrofolate $\left(\mathrm{CH}_{2}\right.$-THF), which is a major one-carbon donor in the cell for the synthesis of methionine and S-adenosylmethionine (SAM), purines, $\mathrm{N}$-formylmethionine-tRNA (fMet-tRNA) and thymidylate (dTTP) $[9,10]$. Thus TMP treatment leads to the loss of THF pools to dihydrofolate because of thymidylate synthesis. This causes concomitant starvation of glycine, methionine, purines, dTTP (folate dependent metabolites) and fMet-tRNA, with some metabolites being depleted faster than others $[11,12]$, and results in nearly complete cessation of DNA, RNA and protein synthesis $[11,13,14]$. Other pathways affected due to depletion of SAM, a major

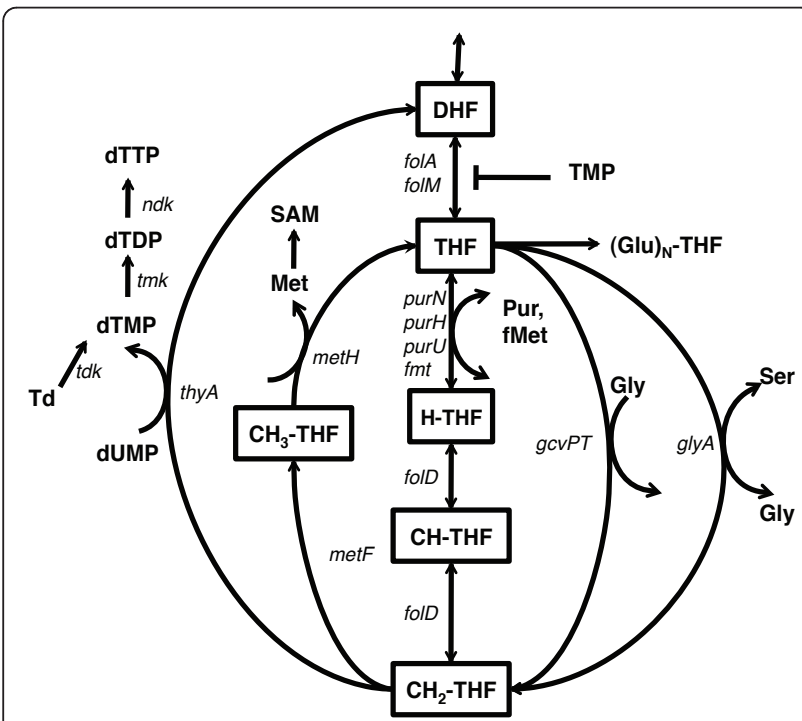

Figure 1 Overview of tetrahydrofolate metabolism. DHF: dihydrofolate; THF: tetahydrofolate (glu) ${ }_{1}$; H-THF: formyltetrahydrofolate; CH-THF: 5,10-methenyltetrahydrofolate; $\mathrm{CH}_{2}$-THF: 5,10-methylenetetrahydrofolate; $\mathrm{CH}_{3}$-THF: 5-methyltetrahydrofolate; Met: methionine; Ser: serine; Gly: glycine; SAM: Sadenosylmethionine; Td: thymidine; Pur: Purines; fMet: N-methionyltRNA ${ }^{\text {fmet }}$. methyl group donor, include synthesis of cofactors, fatty acids and polyamines. Starvation of cells for purines and amino acids is usually bacteriostatic; starvation of dTTP alone leads to loss of viability and is known as "thymineless death" [15-17]. Therefore, cellular outcome of TMP treatment depends on the balance of folate dependent metabolites in the cell and on the media supplementation conditions; cell death depends upon the right combination of supplementation regimes resulting, in part, in thymine starvation $[15,16]$. Thus in controlled environment in the laboratory, the outcome of TMP treatment can in principle be correlated with the composition of the growth medium. However, despite a general understanding of the drug mechanism, the following key aspects of the antibacterial activity of TMP remains unknown: i) what is the molecular nature of folate stress induced by the drug?; ii) what is the relationship between the folate stress and media composition?; iii) what are the similarities and differences between bacateriostatic and bactericidal signatures of the TMP effects.

To answer these and related questions, we treated Escherichia coli with TMP in a variety of media and supplementation conditions and tracked global transcriptional responses using microarrays. We also applied a genome-wide genetic screen to identify gene knockout mutants with decreased or increased susceptibility to TMP in rich media. We observed that the drug treatment, either in minimal medium supplemented with requisite amino acids and adenine or in complex medium (LB), resulted in the loss of viability and this loss was correlated with the induction of DNA damage repair genes. Under limited supplementation conditions (only amino acids or purines) in minimal media, the primary signature was that of stress response, but when both were added in absence of thymine, the stress response signature was not observed. Addition of individual supplements (amino acids or purine) also led to the repression of the respective biosynthetic genes, even in the presence of TMP. We also identified a signature of gene set activity, including induction of DNA damage response, pyrimidine nucleotide biosynthesis and antibiotic stress responsive MarR targets to be most associated with cell lethality in minimal media. However, only the SOS response was associated with the bactericidal outcome across all tested nutrient conditions, including thymine starvation in a thymine auxotroph.

Using a genome-wide collection of knock-out mutants to screen for genetic, rather than environmental, factors that can affect TMP susceptibility, we found that the deoxyribose nucleotide salvage pathway has the capacity to modulate and mediate the effect of the drug. The $\operatorname{deo} A$ and $d e o C$ gene knock-out mutants were found to be resistant to TMP in complex medium, whereas the 
loss of their transcriptional repressor deoR rendered bacteria more sensitive to the drug. However, this relationship was reversed in minimal medium with supplements. This reversal was also observed at the transcriptional level wherein the $d e o C A$ genes were down-regulated during TMP treatment in LB medium and up-regulated in M9 minimal medium. Using this data and other available information we propose that the nucleotide salvage pathway encoded by $\operatorname{deo} C A B D$ genes is a critical modulator of physiological outcomes of the TMP treatment in E. coli.

\section{Methods}

\section{Growth conditions}

Escherichia coli MG1655 F lambda ilvG $\mathrm{F}^{-} \mathrm{fb}-50 \mathrm{rph}^{-}$ was used as a wild-type strain in all experiments. Trimethoprim (Fluka (Sigma-Aldrich), St. Louis, MO) stock solution was prepared by dissolving the drug in distilled water with $1 \% \mathrm{v} / \mathrm{v}$ glacial acetic acid (for Keio screen) or by dissolving in $50 \% \mathrm{v} / \mathrm{v}$ ethanol-chloroform mixture (for transcriptional profiling) and stored in small aliquotes at $-20^{\circ} \mathrm{C}$. Complex medium for cell growth was LB (Luria Bertani broth) and minimal medium was M9 minimal medium with $0.4 \%$ glucose [18]. In LBTMP experiments, cells were treated with $50 \mu \mathrm{g} / \mathrm{ml}$ of TMP, while for M9 experiments the concentration used was $25 \mu \mathrm{g} / \mathrm{ml}$, corresponding to the $\mathrm{MIC}_{50}$ determined in the respective media after $18 \mathrm{hrs}$ of treatment. Amino acids for supplementation (methionine and glycine) were purchased from Fluka (Sigma-Aldrich, St. Louis, $\mathrm{MO}$ ) and stock solutions were prepared in water. Standard cultures were grown in flasks at $37^{\circ} \mathrm{C}$ under aeration in a rotary shaker either in M9 minimal medium containing $0.4 \%$ glucose or in LB liquid medium. For M9 with folate dependent supplementation experiments, the following chemicals were added with a final concentration of $50 \mu \mathrm{g} / \mathrm{ml}$ : adenine, amino acid (methionine and glycine) mixture, and thymine.

\section{Microarray experiments}

Overnight cultures were resuspended in fresh medium and TMP was added when the optical density (O.D. $600 \mathrm{~nm}$ ) of the culture reached 0.3-0.4. Time-point samples were taken every 15-30 minutes from 15 minutes to 2 hours post treatment. The samples were spun down and snapfrozen in liquid nitrogen before storing at $-80^{\circ} \mathrm{C}$ until required. Total RNA samples were purified using the Qiagen RNeasy kit (Chatsworth, CA) according to the manufacturer's protocol. To identify genome-wide gene expression profiles, relative mRNA levels were determined by parallel two color hybridization at single-gene resolution to whole-genome $E$. coli $\mathrm{K}-12$ MG1655 spotted DNA microarrays, designed, printed and probed as described [19], and containing discrete sequence elements corresponding to 98 and $3 / 4 \%$ of all annotated open reading frames (ORFs). Fluorescence DNA probes were synthesized from 10 15 $\mu \mathrm{g}$ of total RNA with random hexamers and Cy-5 dUTP or Cy-3 dUTP dyes (Amersham) and hybridized to microarrays for 6 hours at $65^{\circ} \mathrm{C}$ followed by a washing step as described previously [19]. All microarray experiments were designed as time courses, using the $0 \mathrm{~min}$ time point sample as a common reference. The hybridized arrays were then scanned and the raw fluorescence intensity data were normalized in R (http:// cran.r-project.org/) using the Limma (Bioconductor) package [20] to remove spatial and array based biases. The data was converted to log-ratios of normalized intensity at each time point to time point 0 . The microarray data was uploaded to NCBI GEO database and is available for download through accession number GSE32562.

\section{Gene Set Analysis}

To analyze gene expression data in the context of known gene sets and pathways, we obtained gene functional classification information from databases (GenProtEC [21], RegulonDB [22], EcoCyc [23]) to assemble a total of 480 gene sets (Additional File 1). These comprise of sets of genes whose products are involved in the same pathway and sets of genes that share common regulators or other properties. Normalized gene expression data was analyzed for gene set activity using a method modified from Tian et al [24]. We then modeled the normalized set scores across the entire time series to analyze the effect of individual supplements on gene set activity and to infer set activity associated with the lethal phenotype. The raw gene set score for $k^{\text {th }}$ gene set was calculated as:

$$
S_{k}=\sum_{i=1}^{N_{k}} w_{i} T_{i}
$$

where $w_{i}$ corresponds to the contribution of gene $\mathrm{i}$ within a set to the principal eigenvector of the set across a compendium of experimental conditions [25] and $N_{k}$ is the number of genes in gene set $k$. The weights allow us to consider sets that only have a subset of actively transcribed genes or sets with genes showing opposite but coordinated trends [26,27]. The score $S$ was normalized under two sets of hypothesis $Q_{1}$ and $Q_{2}$ [24], corresponding to testing against random genes and random phenotypes, to yield two normalized gene set scores for each gene set. This was done by randomly sampling genes (in $Q_{1}$ ) or conditions (in $Q_{2}$ ) and then calculating the bootstrapped scores under these permutations. These null scores are normalized to mean 0 and standard deviation 1 to account for gene set size dependence of the distributions. The observed gene set scores $S_{k}$ were also normalized using the parameters of the null distributions. P-values calculated for both $Q_{1}$ and 
$Q_{2}$ scores were converted to posterior probability (PP) of significance, which is mathematically equivalent to the local False Discovery Rate (FDR) value of the score [28], and PP values from both hypotheses were multiplied, under assumption of independence, to yield the final PP for the gene set. PP values of greater than 0.90 (estimated FDR 5\%) were considered to be highly significant. The normalized scores in the two hypotheses for gene set were averaged to yield a enrichment score (ES), which allows us to quantitatively compare two or more gene sets within a condition or a gene set across conditions, and its sign indicates the direction of change (up- or down-regulation) within the set. To infer effects of individual supplementation, the set scores (ES) for the entire time series of M9 treatments were modeled as:

$$
E S_{i}=\beta_{i}^{A A} A A_{i}+\beta_{i}^{A d} A d_{i}+\beta_{i}^{T h y} T h y_{i}+\varepsilon_{i}
$$

where $\mathrm{ES}_{\mathrm{i}}$ is the vector of set scores of set $i, \mathrm{AA}_{\mathrm{i}}, \mathrm{Ad}_{\mathrm{i}}$ and $\mathrm{Thy}_{\mathrm{i}}$ are factors with level 1 (if the respective supplements are added) or 0. M9TMP condition has all three factors at level 0 since none of the supplements were added. A positive coefficient for any factor indicates that the addition of the supplement is associated with increase in set score relative to its baseline level.

For inferring associations with cell lethality, set scores from both LB and M9 experiments were considered. To account for the influence of latent variables affecting the set scores, surrogate variable analysis (SVA, [29]) was used to model the hidden variables as a covariate:

$$
E S_{i}=\beta_{i}^{S V} S V_{i}+\beta_{i}^{\text {Phe }} P h e_{i}+\varepsilon_{i}
$$

where $\mathrm{ES}_{\mathrm{i}}$ is the vector of set scores for set $i, \mathrm{SV}_{i}$ are surrogate variables and $\mathrm{Phe}_{i}$ represents a vector of phenotypes associated with the set (factor with two levels: "cidal" or "static"). Parametric p-values associated with the estimated coefficients $\beta_{i}^{\text {Phe }}$ were obtained by ANOVA, and False Discovery Rates (q-value [30]) was calculated to infer significant gene sets. A q-value of 5\% indicates all sets with the same or lower q-value are called significant at 5\% False Discovery Rate. All calculations were done in R. Non-parametric classification based on Receiver-Operator Characteristics (ROC) curves were done by using the $\mathrm{R}$ package "caTools"[31]. AUC values of 0.85 and higher were considered significant, and it was used as the second threshold to filter significant gene sets. The entire data and the $\mathrm{R}$ code to reproduce the analysis can be found in Additional File 2.

\section{Genome-wide genetic screen}

The Keio collection was a kind gift of Prof. Hirotada Mori and consists of knock-out mutants of 3985 genes of E. coli strain BW25113 [32]. The knock-out mutants contain $\operatorname{Kan}^{\mathrm{R}}$ cassettes inserted in genes using the method of Datsenko and Wanner [33]. For mutant screening, a copy of the mutant plates was made by replica inoculating the frozen stocks into 96-well plates containing $150 \mu \mathrm{l}$ of LB medium and incubating them at $30^{\circ} \mathrm{C}$ for $12-18$ hours with intermittent shaking. For growth and inhibition experiments, the optical density in the wells of the 96-well plate was measured using Victor3 plate reader (Perkin-Elmer). The actual O.D. reading in the plate reader depends on the medium and the volume of liquid in the wells and is correlated with actual culture density measured by conventional light scattering techniques $\left(\mathrm{r}^{2}>0.99\right)$ for O.D. 0.1-1.0. Since each plate was inoculated as a set, there was plate-toplate variation in O.D. that was accounted for by normalizing across plates. Resistant and sensitive mutants were identified by normalized O.D. readings. Mutants in Keio collection are in BW25113 background. For individual mutant analysis, the $\operatorname{Kan}^{R}$ insertion alleles were transferred into wild-type MG1655 background using P1-transduction [34]. An E. coli thyA715 mutant MG1655 was obtained from CGSC. Different deo mutations were similarly introduced into the thy $A^{-}$parental strain. thy $A^{-} d e o^{-}$double mutants had different thymine/ thymidine growth requirements; thy $A^{-} 20 \mu \mathrm{g} / \mathrm{ml}$ thymine, thy $A^{-}$deo $A^{-} 20 \mu \mathrm{g} / \mathrm{ml}$ thymidine, thy $A^{-}$deo $C^{-} 2 \mu \mathrm{g} /$ $\mathrm{ml}$ thymine, thy $A^{-}$deo $R^{-} 50 \mu \mathrm{g} / \mathrm{ml}$ thymine $[35,36]$ For viability experiments and RNA sampling, the cultures were handled as follows. Cells were grown to stationary phase in LB or M9 minimal media (with glucose). They were then inoculated in fresh medium and grown till $\mathrm{O}$. D. 0.4-0.6 before treatment. For TMP treatment in LB, TMP was added to appropriate final concentrations. For TMP treatment in minimal medium, growing cultures were diluted in pre-warmed fresh minimal medium containing TMP and methionine, glycine, adenine supplements. For viability counts, samples were diluted in $0.9 \% \mathrm{NaCl}$, spread or spotted on LB plates and incubated 12-16 hours before colony counts were taken.

\section{Results and Discussion}

\section{Folate supplementation regimes determine bacterial} viability phenotypes

The effect of antibiotic trimethoprim (TMP) on bacteria depends on the treatment conditions. To characterize the cellular responses associated with these effects, we treated $E$. coli with the antibiotic in different growth and supplementation conditions: complex medium (LBTMP), minimal medium M9 (M9TMP), and minimal medium supplemented with folate dependent metabolites, amino acids methionine and glycine (M9TMPAA), adenine (M9TMPAd), amino acids and adenine (M9TMPAdAA), and M9 supplemented with the amino acids, adenine and thymine (M9TMPThyAdAA) (Table 
1). These conditions were chosen based on their causing different outcomes in TMP treatment: only in minimal medium the treatment results in growth arrest, supplementation with both AA and Ad leads to cell killing, and addition of thymine rescues cells from the effects of the drug [15]. We followed the effects of the drug treatment by monitoring colony formation, as a proxy to cell viability, and genome-wide transcriptional responses, as a proxy to physiological changes elicited by the drug. As expected, cell viability in minimal medium depended on supplementation of the folate-derived metabolites. TMP treatment in M9 resulted in cessation of growth without a loss of viability, whereas M9TMPAdAA condition resulted in killing (Table 1) after a lag period, along with increase in cell mass due to filamentation (data not shown). Thymine supplementation prevented viability loss in the bacterial culture, confirming that the primary mechanism of TMP induced cell death is due to thymine starvation [15]. Incomplete supplementation either by the amino acids or by the purine resulted in bacteriostasis. LBTMP condition resulted in loss of viability after a lag period of approximately $120 \mathrm{~min}$, as well as in filamentation.

\section{Effects of individual supplementation regimes}

Given the diverse nature of phenotypes generated by the combination of TMP and media conditions, and the complex nature of folate metabolism being perturbed, it is essential to identify key molecular events during each treatment that are associated with the observed phenotype. We first followed transcriptional responses to TMP treatment in these conditions as a time series using cDNA microarrays and obtained gene expression profiles as ratios of transcript abundances after the treatment (10 - 120 minutes) normalized to the before-treatment levels (0 minutes). To develop a biological interpretation of these responses, we examined transcriptional activity of sets of genes [24]. Briefly, for each time point in each condition, the activity score $\left(S_{k}\right)$ for each gene set was calculated as the weighted average of all the genes within the gene set (Methods). The score was then normalized using background null distributions [24] to get the enrichment scores (ES) and the p-values for these scores were then converted to a posterior probability (PP, [28]) to adjust for multiple testing. The PP value (1 for strong enrichment, 0 for no enrichment), along with the enrichment score ES, allowed for quantitative comparison of different gene sets in different conditions. PP values of greater than 0.90 were considered to be highly significant for gene set activity, corresponding to false discovery rates of less than $5 \%$ for the conditions.

The effect of TMP in different supplementation conditions can be viewed and analyzed as an interaction between the effects of the drug effect and the condition. Traditionally, the effect of a drug would be ascertained in cultures adapted over multiple generations to their growth environments. While such approach may seem physiologically most sound, it does not allow determining the media specific effects in any straightforward way, in part because of a prolonged adaptation and resulting steady state are accompanied by macroscopic growth and metabolic differences which can mask nutrient-specific regulation. This has not been seen as a serious problem since for most actively studied antibacterials, the media composition either does not have an effect on the outcome of the treatment or its effects are not known. This however would be a serious problem for TMP treatments where media composition effects have been well documented. Therefore we designed our experiment in a way that yielded physiologically meaningful, and consistent with historical data, media-dependent outcomes of the treatments and also allowed detecting direct regulatory effects of the supplementations. According to such design, the drug was added to the cell cultures along with the supplements and transcriptional responses were recorded immediately afterwards. Thus the ensuing regulatory and physiological changes in the cells will be, by definition, a result of the combinations, or interactions, of the effects of the drug and supplements. Modeling these transcriptional responses as estimated additive effects of each supplement could help us explain these interactions as simple cause and effect representation for each individual factor-gene set pair.

Table 1 Treatment regimens used for gene expression analysis

\begin{tabular}{llll}
\hline Condition & Base medium & Supplementation & Viability loss \\
\hline LBTMP & Luria-Bertani broth & - & + (90\% loss in 3 hours $)$ \\
M9TMP & Minimal M9 & None & - \\
M9TMPAdAA & Minimal M9 & Met, Gly, Ad & $+(>70 \%$ loss in 6 hours $)$ \\
M9TMPAA & Minimal M9 & Met, Gly & - \\
M9TMPAd & Minimal M9 & Ad & - \\
M9TMPThyAdAA & Minimal M9 & Met, Gly, Ad, Thy & - \\
\hline
\end{tabular}

A list of treatment regimens used. Viability loss indicates the relative magnitude of cell lethality (+: maximum, -: no loss). TMP: Trimethoprim (50 or $25 \mu \mathrm{g} / \mathrm{ml}$ ), Met: methionine, Gly: glycine, Ad: adenine (each at $50 \mu \mathrm{g} / \mathrm{ml}$ final concentration) 
To analyze the effects of individual supplements (AA: met, gly, Ad: adenine and Thy: thymine) on the TMPinduced folate stress, we employed a linear model using set scores across all time points for each condition and with individual supplements as factors, to identify the gene sets with the highest absolute coefficients associated with each factor. In total, 16 overlapping gene sets have been identified with a significant coefficient in at least one condition (Additional File 3). The sets have been grouped based on the similarity of associated coefficients across all conditions into eight clusters (Figure 2): 1-histidine and glycine metabolism; 2 - sulfate assimilation; 3 - general stress response; 4 - methionine transport and metabolism; 5 - DNA damage response and repair; 6 - purine biosynthesis; 7 - protein synthesis machinery; 8 - enterochelin biosynthesis. TMP, by virtue of its anti-DHFR mechanism, triggers different starvation responses depending on the exogenous supply of respective metabolites, as evidenced from the variations in the activity of the most responsive gene sets (Figure $2 \mathrm{~A}-\mathrm{E})$. Without any supplementation, the drug induced amino acid and nucleotide starvation which could be characterized by severe down-regulation of ribosomal and purine biosynthetic genes, transient up-regulation of the methionine cluster of genes, and by late and minimal up-regulation of the damage response cluster (Figure 2A). Targets of RpoS, a stress signal responsive regulator, were also significantly up-regulated in this condition ( $\mathrm{PP}>0.998$ ), indicating that starvation for amino acids and nucleotides was followed by a general stress response in the cells. Starvation for amino acids and thymine (Figure 2B) was characterized by the down-regulation of the purine cluster and up-regulation of the methionine cluster. Addition of adenine also lowered the extent of repression of genes encoding translation proteins as compared to TMP alone. Starvation for thymine and purines (Figure 2C), on the other hand, resulted in relative down-regulation of the methionine and sulfate assimilation clusters and in an up-regulation of glycine cleavage pathway as a response to added glycine, and in a moderate, more pronounced than in the TMP alone condition, but late up-regulation of the DNA damage genes. Histidine biosynthesis was also upregulated relative to the conditions without $\mathrm{AA}$, which is an expected response to external methionine [25]. When cells were starved only for thymine (Figure 2D),

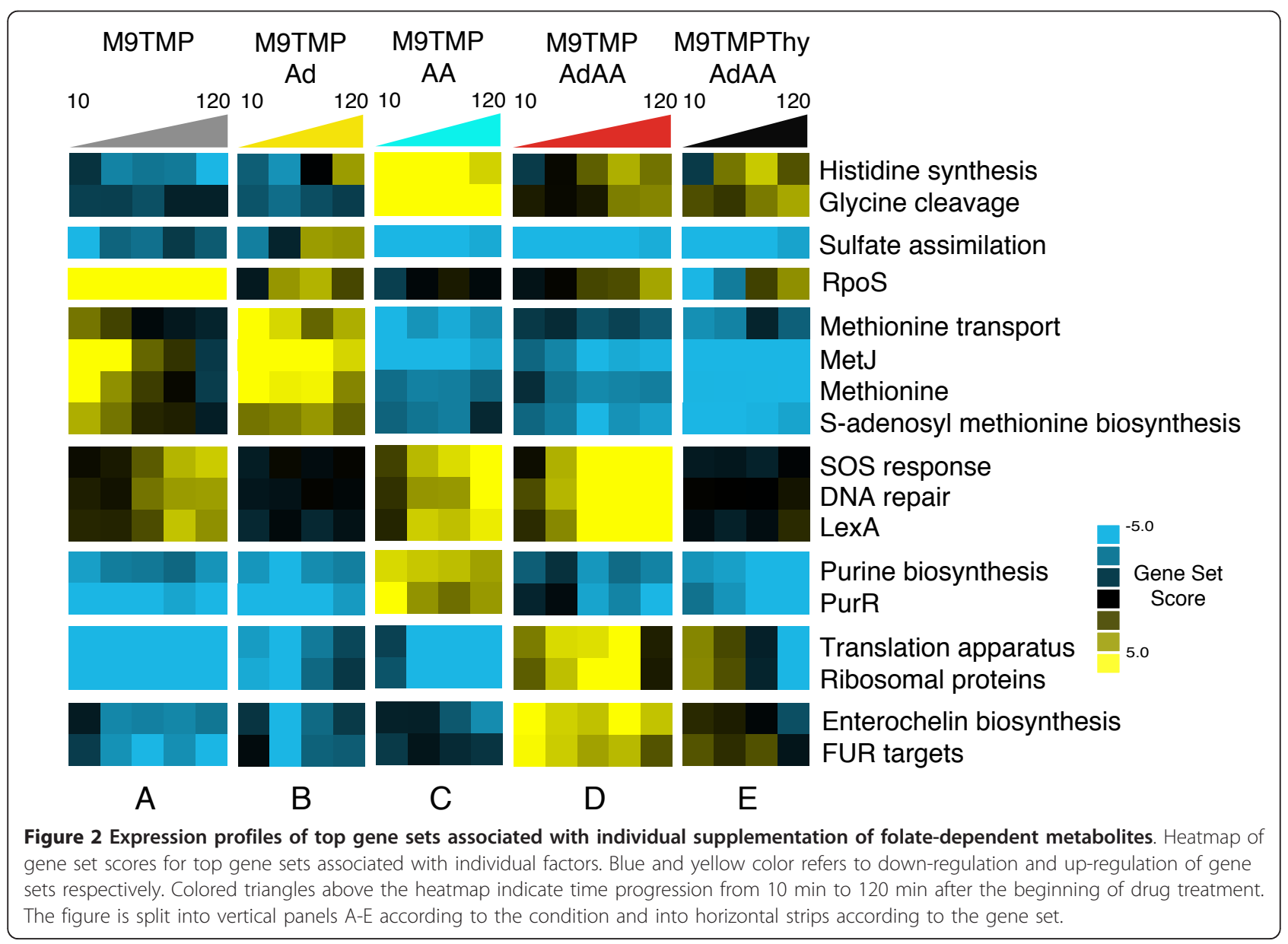


three clusters were characteristically up-regulated: DNA damage, protein and enterochelin synthesis. Other gene clusters in this condition were either unaffected or down-regulated. Addition of thymine along with other supplements (Figure 2E) prevented the inductions observed in the thymine starvation. However, thymine supplementation had no effect on the activity of genes controlling purine biosynthesis, sulfate assimilation, as well as amino acid transport and metabolism. Thus thymine counteracted the antibacterial effect of TMP and suppressed DNA damage response and transcriptional over-drive of genes involved in protein synthesis. At the same time, specific regulatory responses associated with the addition of adenine or amino acids were not complemented by the nitrogen base.

\section{Identification of a transcriptional signature associated with lethality}

The analysis presented in the above section supports the notion that TMP regulatory effects can be complemented by different metabolic supplements. Since, on the other hand, supplementation regimes are known to elicit different phenotypic outcomes of the drug treatment, it follows, from the transitivity principle, that the regulatory effects should be associated with the outcomes. However, since the above analysis included only one bactericidal condition (M9TMPAdAA), we chose to boost the power of our association analysis by adding another bactericidal condition: TMP treatment in LB. To determine which pathway responses were most associated with the phenotype of rapid loss of viability, we classified the gene set scores according to the lethality phenotypes, i.e. large ( $>50 \%$ of the treated population) loss of viability in M9TMPAdAA and LBTMP vs. no or minimal loss $(<10 \%)$ in M9TMPThyAdAA, M9TMP, M9TMPAd and M9TMPAA (Figure 3). The top gene sets associated with the phenotype were related to DNA damage response (partially overlapping Multifun categories: DNA repair and SOS response and targets of LexA; FDR < 0.01\%; Additional Files 4, 5) and DNA recombination, which were up-regulated in the bactericidal conditions as compared to no change in the static conditions. Other gene sets in the top category comprised of ribosomal proteins, targets of MarR (multiple antibiotic resistance response), enterochelin biosynthesis, OxyR targets and pyrimidine biosynthesis (up in cidal,

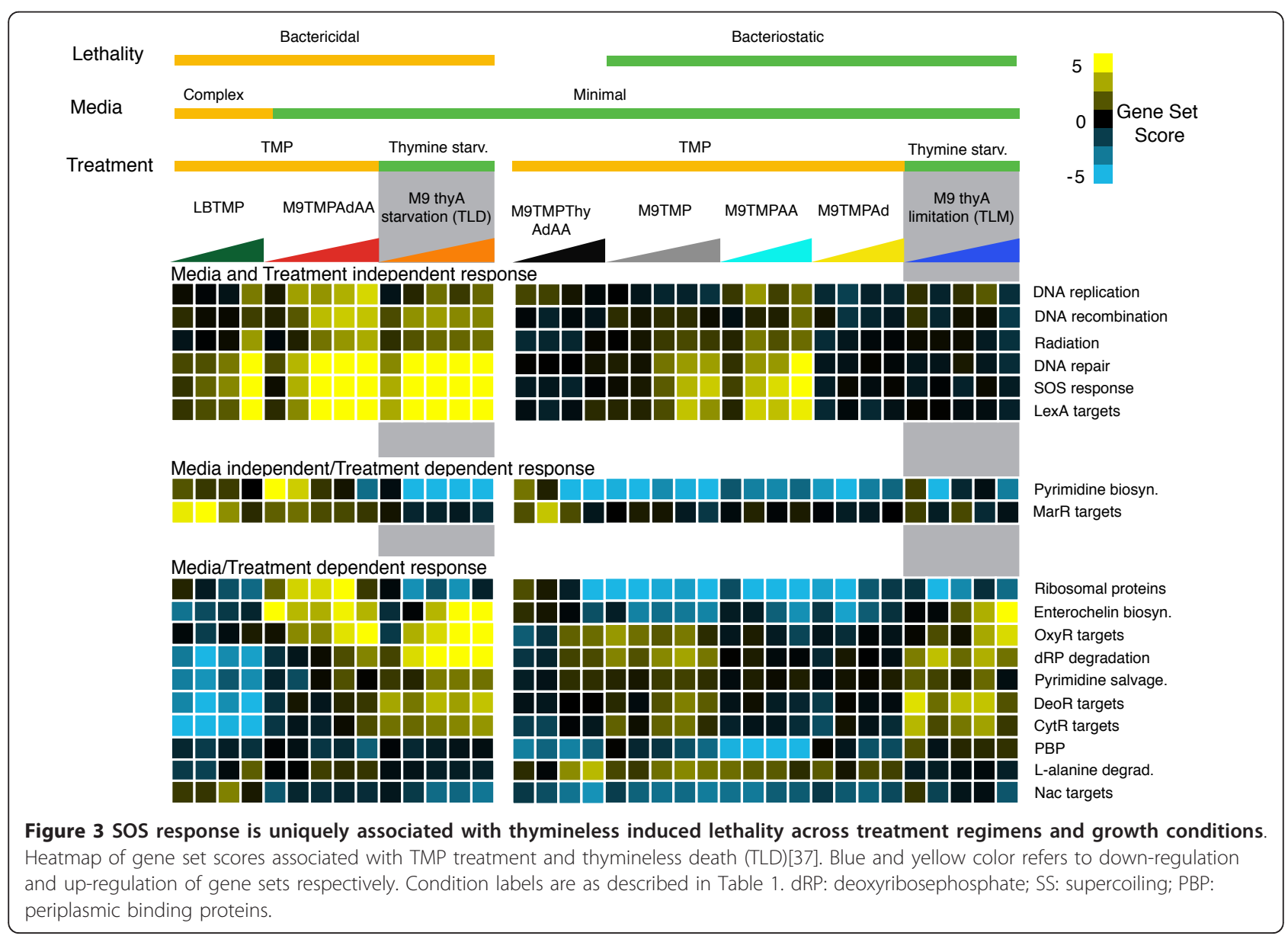


down or no change in static; "TMP treatment" in Figure 3 , Additional Files 4, 5). This was in contrast with genes in deoxyribose nucleotide salvage pathways (including targets of CytR and DeoR) which were down-regulated in cidal conditions compared to the static. In particular, the salvage pathways were strongly down-regulated in complex LB medium. Iron uptake associated enterochelin biosynthesis, periplasmic binding proteins and targets of nitrogen assimilation regulator $\mathrm{Nac}$ were relatively down-regulated in the static conditions compared to cidal. Since the significance of the association depends on the scale of the calculated set scores, we also implemented a non-parametric classification method based on receiver-operator characteristics (ROC) to identify the specificity and sensitivity of phenotype prediction (AUC score) based on individual set scores. When top ranked gene sets from both methods, based on FDR for association and the AUC value for ROC-based classification, were combined by averaging the top gene set ranks, there was a significant overlap between the gene sets ranked by both methods (Spearman rank correlation over all gene sets $=0.96, \mathrm{p}$-value $<10^{-16}$; Additional File 6). When the responses of these top pathways were compared across all examined conditions (cidal and static conditions and complex and minimal media), transcription of only three non-redundant sets - SOS and related DNA damage gene classes, pyrimidine biosynthesis and MarR targets - was affected by the drug in the same direction, i.e., these pathways were up-regulated in each TMP-induced bactericidal condition ("TMP Treatment" in Figure 3). Directionality of transcriptional responses of the rest of the pathways depended on the media. For example, salvage pathways of deoxyribonucleotides, which were significantly associated with lethality, were down-regulated in LBTMP, but were not affected in M9TMPAdAA and were only moderately up-regulated in the static conditions. Similarly, ribosomal proteins were moderately down-regulated in LBTMP but strongly up-regulated in M9TMPAdAA. Thus, SOS response, pyrimidine biosynthesis and MarR targets, which controls transcription of genes involved in multidrug efflux, form the media independent signature responses associated with the bactericidal effect of the antibiotic.

To further compare transcriptional sensitivities of these gene sets, we scored their responses in another thymine starvation condition, triggered by thymine withdrawal from a thyA strain ("Thymine starvation" in Figure 3). We observed that the SOS response followed the up-regulation trend following the treatment, while pyrimidine biosynthesis was down-regulated and MarR targets were not affected. Thus, we propose that the induction of the DNA damage response is the only transcriptional effect associated with thymineless death phenomenon observed across a variety of experimental conditions including thymine starvation of auxotrophic mutants, starvation of dTMP using TMP in the presence of supplements or using TMP in complex growth media; whereas up-regulation of pyrimidine synthetic genes and MarR targets is associated with lethality only in TMP treatments. Of note, when we examined a compendium of expression profiles for activity of the MarR regulon, we observed that other top conditions in which MarR targets were up-regulated were treatments with antibacterials and antibiotics including Norfloxacin, Streptomycin, Kanamycin, Indole-acrylate and Chloramphenicol (data not shown). Since all of these treatments were carried out in $L B$, and the current identification of the MarR signature was driven by the LBTMP condition, it is possible that de-repression of MarR targets is a result of interaction(s) between yet unidentified factors associated with growth in a rich medium and the generic antibiotic induced stress.

We previously reported that the DNA damage response was the primary transcriptional response that separated thymine starvation leading to thymineless death (TLD) in thyA auxotrophs from the thymine limitation (TLM) wherein cells were supplied with suboptimal amounts of thymine [37]. Here, we showed that the SOS response was also significantly associated with cell death by TMP in minimal medium supplemented with folate metabolites or in complex medium. The genes involved in SOS response were observed to be significantly induced in bactericidal conditions as compared to static conditions after 30 minutes of treatment (Onesided t-test $\mathrm{p}$-value $=0.004)$ and at later time points. No loss of viability was observed in cidal conditions in either media at this time point, indicating that DNA damage precedes viability loss and thus may be causative to cell lethality.

\section{Genome-wide genetic screen for TMP susceptibility}

To complement a genome-wide transcriptional survey, we assessed the relative fitness contribution of individual gene products under TMP stress by using a forward genetic screen. To do so, we used the Keio collection of Escherichia coli BW25113 knock-out strains affecting 3985 individual genes [32] to screen for mutants whose growth was resistant or sensitive, as compared to wildtype, to sub-lethal concentration of TMP in LB complex medium. After 24 hours of incubation, the final yield of biomass of the mutants was measured as optical density (O.D.) using a plate reader. Since the mutants were arranged in 96-well plates randomly, outliers on each plate were identified as normalized O.D. readings that deviated significantly from the average on each plate. A list of top 100 resistant and sensitive candidates was assembled from all plates and was compared to a 
replicate assay. The O.D. of the highest yielding mutants was on average 6-fold higher than that of the lowest mutants in this sub-lethal concentration, and were about $70 \%$ higher than the average mutant. A total of 18 and 13 gene knock-outs had reproducible high-yield (enrichment $\mathrm{p}$-value $\left.<10^{-16}\right)$ and low-yield $\left(\mathrm{p}<10^{-6}\right)$ phenotypes, respectively, and are listed in Tables 2 and 3.

The gene $t d k$ encodes thymidine kinase, which converts thymidine to thymidine monophosphate dTMP (Figure 1). In the absence of $t d k$, cells exclusively rely on tetrahydrofolate dependent conversion of dUMP to dTMP, which is inhibited during TMP treatment. Cells without $t d k$ should be therefore unable to grow, and indeed a $t d k$ knock-out was identified as a sensitive mutant in the assay. This was verified by the observation of rapid loss of viability of $t d k$ mutant after $50 \mu \mathrm{g} / \mathrm{ml}$ TMP addition in liquid culture (data not shown). Other mutants imparting sensitivity to TMP included several knock-outs of the genes of chemotaxis pathway $(f l i D$, $f l i L, f l i N, f l g H)$ and of $h d a$, a regulatory inhibitor of the

\section{Table 2 List of mutants yielding high biomass in presence of TMP at sub-lethal concentrations in LB medium}

\begin{tabular}{|c|c|c|}
\hline \multicolumn{3}{|c|}{ Resistant knock-out candidates } \\
\hline Gene & $\begin{array}{l}\text { Gene } \\
\text { ID }\end{array}$ & Description \\
\hline moaE & b0785 & $\begin{array}{l}\text { Molybdopterin (MPT) synthase, large subunit; chlorate } \\
\text { resistance; dimer of dimers with MoaD }\end{array}$ \\
\hline ybhN & b0788 & Function unknown \\
\hline ylie & b0833 & Function unknown \\
\hline ymfQ & b1153 & Function unknown \\
\hline yobG & b1826 & Function unknown \\
\hline yecN & b1869 & Function unknown \\
\hline $\mathrm{crr}$ & b2417 & $\begin{array}{l}\text { Phosphocarrier protein for glucose of the PTS; Enzyme } \\
\| \mathrm{A}(\mathrm{G} \mid \mathrm{c}) \text {; formerly Ell }(\mathrm{g} \mid \mathrm{c})\end{array}$ \\
\hline recJ & b2892 & Single-stranded DNA-specific exonuclease, 5'-3' \\
\hline ygj & b3088 & $\begin{array}{l}\text { Function unknown; induced by alkali; putative } \\
\text { membrane transport or efflux protein }\end{array}$ \\
\hline ygjU & b3089 & $\mathrm{Na}+$ /serine (threonine) symporter \\
\hline nanA & b3225 & N-Acetylneuraminate lyase (aldolase) \\
\hline yhip & b3496 & Function unknown \\
\hline uhpT & b3666 & $\begin{array}{l}\text { Fosfomycin sensitivity; sugar P transport system; } \\
\text { transport protein for hexose P's }\end{array}$ \\
\hline yiiQ & b3920 & Function unknown \\
\hline uvrA & b4058 & $\begin{array}{l}\text { Excision nuclease subunit } A \text {; repair of UV damage to } \\
\text { DNA; LexA regulon; binds Zn(II) }\end{array}$ \\
\hline fimE & b4313 & $\begin{array}{l}\text { Site-specific recombinase for fimA promoter segment } \\
\text { inversion; bias for ON to OFF phase switching }\end{array}$ \\
\hline deoC & b4381 & $\begin{array}{l}\text { Deoxyribose-phosphate aldolase; deoxyriboaldolase; } \\
\text { binds selenium }\end{array}$ \\
\hline deoA & b4382 & Thymidine phosphorylase \\
\hline
\end{tabular}

A total of 18 mutants, based on their relatively high biomass yield in presence of TMP, were identified as sensitive candidates. Genes whose functions are

related to DNA maintenance and nucleotide salvage pathway are highlighted in bold. Genes are sorted by their Gene IDs.
Table 3 List of mutants yielding low biomass in presence of TMP at sub-lethal concentrations in LB medium

\begin{tabular}{|c|c|c|}
\hline \multicolumn{3}{|c|}{ Sensitive knock-out candidates } \\
\hline Gene & $\begin{array}{l}\text { Gene } \\
\text { ID }\end{array}$ & Description \\
\hline deoR & b0840 & $\begin{array}{l}\text { Repressor for deo operon, nupG and tsx; binds } \\
\text { deoxyribose-5-phosphate inducer }\end{array}$ \\
\hline $\mathrm{flgH}$ & b1079 & Flagellar synthesis, basal body L-ring protein \\
\hline fliD & b1924 & $\begin{array}{l}\text { Hook-associated protein 2, axial family; flagellar } \\
\text { regulon }\end{array}$ \\
\hline flil & b1941 & $\begin{array}{l}\text { Cytoplasmic membrane ATPase involved in flagellar } \\
\text { assembly; involved in export of flagellar axial protein } \\
\text { subunits }\end{array}$ \\
\hline fliN & b1946 & Flagellar switch protein \\
\hline JW5799 & - & \\
\hline mdoH & b1049 & Membrane glycosyltransferase \\
\hline tdk & b1238 & Deoxythymidine kinase \\
\hline$y c b C$ & b0920 & Function unknown \\
\hline усім & b1280 & Function unknown \\
\hline ydhA & b1639 & Function unknown \\
\hline $\begin{array}{l}\text { yfgE } \\
\text { (hda) }\end{array}$ & b2496 & $\begin{array}{l}\text { Required for regulatory inactivation of DnaA; } \\
\text { multicopy suppressor of dnaN(ts) }\end{array}$ \\
\hline alas & b2697 & Alanine-tRNA ligase \\
\hline
\end{tabular}

A total of 13 mutants, based on their relatively low yields, were identified as sensitive candidates. Genes whose functions are related to DNA maintenance and nucleotide salvage pathway are highlighted in bold. Genes are sorted by their Gene IDs.

replication initiator protein DnaA. Inactivation of Hda is a major cause of DnaA-dependent over-initiation of the chromosomal replication [38], and recent studies have proposed a link between aberrant DNA replication initiation and TLD $[37,39,40]$. High-yielding mutants could in principle be genuine TMP resistant mutants or strains filamenting in the presence of the drug. Among these mutants were knock-outs of $u v r A$, a nuclease component of the nucleotide excision repair, and of recj, a single strand DNA exonuclease. A loss of recJ function was reported to alleviate the lethal effect of the thymine starvation $[37,39,41]$, which is believed to be the primary bactericidal mechanism of TMP. Knock-outs of two of the genes involved in deoxypyrimidine nucleotide salvage pathway, $\operatorname{deo} C$ and $\operatorname{deo} A$, were found to be among resistant candidates, whereas a knock-out of the repressor of the deoCABD operon, deoR, was found to be more susceptible to TMP. $\operatorname{deo} C$, $\operatorname{deo} A$ and $d e o R$ mutants grew in LB without the drug as well as their isogenic parental strain. Of note, the $\operatorname{deo} C A B D$ operon was down-regulated during LBTMP treatment and was among the top down-regulated gene sets/pathways in the condition. This enrichment of a single metabolic pathway and its regulator in the TMP phenotypic screen along with its transcriptional signature, and given the central role of the pathway in the conversion of thymidine and uridine nucleosides into nucleotides, led us to investigate these genes in more detail. 
The deo operon consists of genes encoding deoxyribose-5-phosphate aldolase (Dra/DeoC), thymidine phoshphorylase (Tpp/DeoA), pentophoshomutase (DeoB) and purine nucleotide phosphorylase (Pnp/DeoD). DeoA catalyzes the reversible interconversion between thymine and thymidine and between uracil and deoxyuridine. The deoxyribose sugar donor is deoxyribose-1-phosphate, which is converted to deoxyribose-5-phosphate (dR5P) by DeoB, and which is then degraded to glycolytic intermediates by DeoC. The operon is under negative control by DeoR. In the presence of metabolic intermediate dR5P, the deo operon is derepressed, leading to increased activity of the salvage pathway $[42,43]$. The knock-out mutations in the deo genes were transferred into MG1655 background by P1 transduction (Methods). First we examined if the growth phenotype of deo mutants translated into viability phenotypes in LB medium (Figure 4A). Viability of exponentially grown wildtype E. coli MG1655 treated with TMP at $50 \mu \mathrm{g} / \mathrm{ml}$ could be described by a typical by-phasic curve: a prolonged (120 $\mathrm{min})$ lag followed by an exponential killing phase, with $17 \%$ of initial colony forming units (CFU) remaining after 3 hours of treatment. The cell mass (O. D.) typically increased 2-4 fold due to cell filamentation (Additional File 7). In comparison, MG1655 deo $A^{-}$culture retained $83 \%$ of the pre-treatment CFU's at the same time, and a deo $C^{-}$culture grew more than $400 \%$ of its original CFU's indicating nearly complete masking of the TMP effect. In contrast, a deoR knock-out sensitized this strain to the drug, resulting in $97 \%$ killing after 3 hours. In a complex medium, bacteria can access extracellular nucleotides and other precursors. It has been shown that the effect of TMP depends on the presence of these precursors in the medium [44]. To check for phenotypes of the deo mutants in a defined minimal medium, we grew cells in M9 supplemented with glucose at $0.4 \%$ and each of the folate dependent metabolites methionine, glycine and adenosine at $50 \mu \mathrm{g} / \mathrm{ml}$. Upon treatment with TMP $(50 \mu \mathrm{g} / \mathrm{ml})$, the deo mutants exhibited the phenotypes opposite to those observed in $\mathrm{LB}$, i.e. $\mathrm{deo} \mathrm{C}^{-}$and $\mathrm{deo} A^{-}$mutants were much more sensitive (6.3\% and $3.1 \%$ surviving CFU, respectively) after 3 hours of treatment compared to wild-type (44\%), whereas deoR $R^{-}$showed an intermediate phenotype with $18 \%$ survival (Figure 4B, Additional File 7). Addition of thymine (thymidine for $d e o A^{-}$) rescued these mutants from TMP. In both conditions, loss of CFU's was accompanied by cell filamentation, indicating a block in cell division (data not shown). In this assay, addition of TMP appeared to have produced a phenocopy of inactivation of thymidylate synthase, ThyA, which is required for conversion of dUMP to dTMP, by starving it for the essential methyl group donor, $\mathrm{CH}_{2}$-THF.

Thus the effect of the deo mutations on TMP activity falls into two categories. One - affects thymidine and thymidine/thymine scavenging from the reach medium. In this category, $\mathrm{deo}^{-}$and $d e o A^{-}$mutant cells were less susceptible to the drug than the wild type under the same treatment conditions by improving anabolism of the nucleoside/nucleotide, and $d e o R^{-}$made cells more susceptible to TMP by de-repressing the thymi(di)ne catabolism. Another - affects catabolism of dUTP/

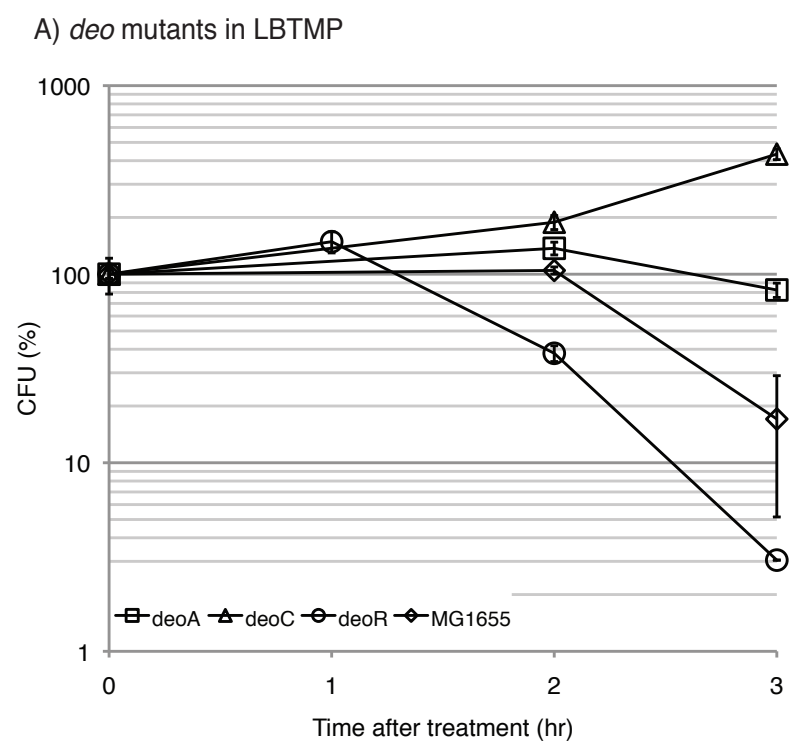

\section{B) deo mutants in M9TMPAdAA}

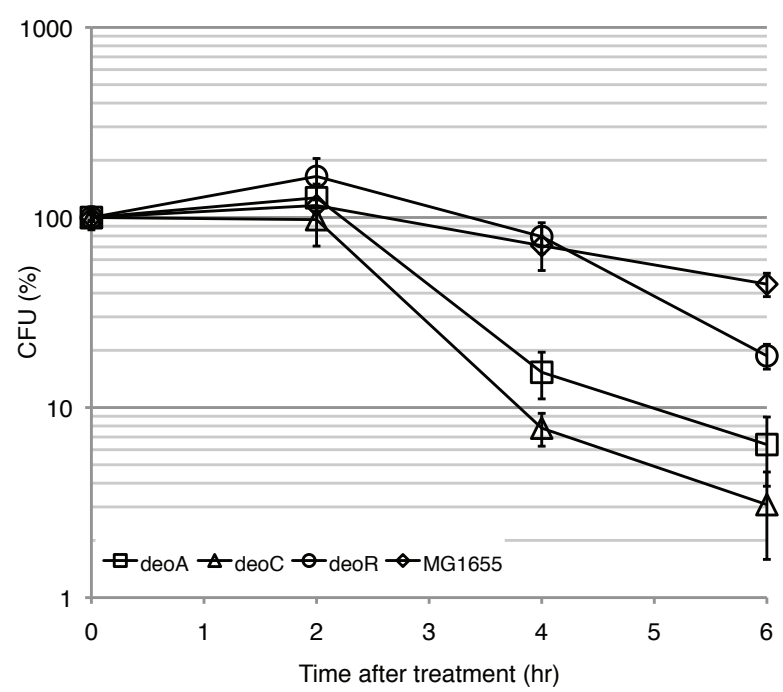

Figure 4 Viability phenotypes of deo $^{-}$and thy A $^{-}$deo $^{-}$mutants in LB and M9 media. A) Mutants in deoC ( $(\Delta)$, deoA ( $(\square)$ and deoR ( 0 ) and wildtype E. coli MG1655 ( $\diamond)$ were treated with $50 \mu \mathrm{g} / \mathrm{ml}$ of TMP in LB medium. Viability was tracked by counting CFU's (on LB plates after 16-hr incubation at $37^{\circ} \mathrm{C}$ ) in the cultures sampled at 1,2 and 3 hours of the treatment. B) In minimal media with supplements M9TMPAdAA. 
$\mathrm{dUMP} / \mathrm{dU}$. In this category, both $\operatorname{deo} \mathrm{C}^{-}$and $\operatorname{deo} A^{-}$ mutants were more susceptible to the drug action in the minimal medium, where bacteria "relies" solely on de novo pyrimidine synthesis. In more detail, the phenotypes of the deo operon may be understood by examining the nucleotide salvage pathway (Figure 5). In the presence of exogenous deoxyribose pyrimidines, the pathway catabolizes the ribose sugars to form glyceraldehyde-3-phoshpate and acetaldehyde to be used in central carbon metabolism. However, during thymine starvation in thy $A^{-}$mutants and TMP treatment, the cell salvages thymine, or thymidine, from the medium using dR1P. In LBTMP condition, $\mathrm{CH}_{2}$-THF will eventually deplete as cells run out of folate dependent metabolites, causing dTMP (and hence dTTP) insufficiency. LB medium contains thymidine (as ascertained by the sustained growth of thy $A^{-} \operatorname{deo} A^{-}$and thy $A^{-}$strains in the medium), which is utilized. However, since thymidine is catabolized to $\mathrm{dR} 1 \mathrm{P}$ and its catabolic products, the equilibrium of thymidine/thymine reversible conversion by thymidine phosphorylase (DeoA) should be shifted toward thymidine catabolism. Since thymidylate is catabolized, cells eventually starve for dTTP and lose viability. The deo operon is down-regulated in the LBTMP condition as compared to before treatment, suggesting depletion

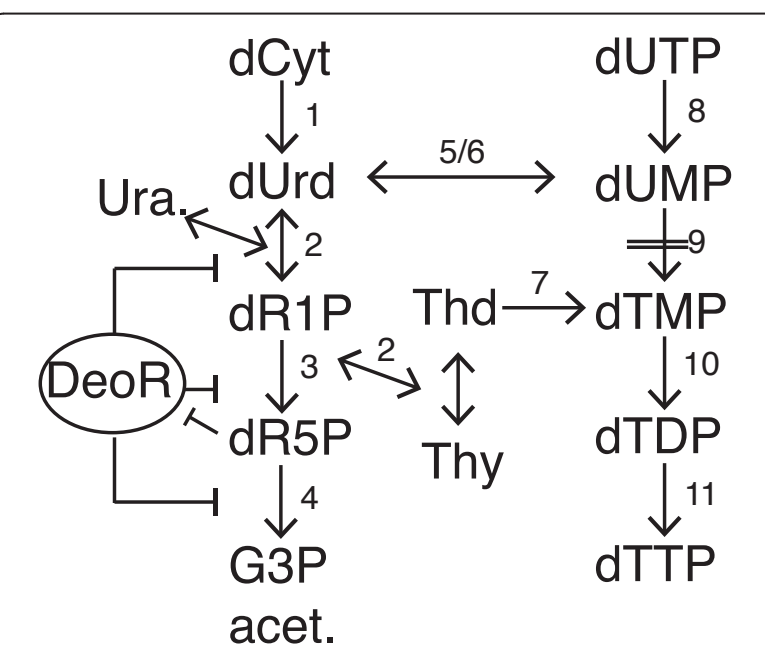

Figure $\mathbf{5}$ Schematics of a pyrimidine salvage pathway. Model of deoxyribose nucleotide salvage pathway. Double dashed line indicates block in a pathway due to gene deletion or in case of pathway 9 (dUMP $\rightarrow$ dTMP), block in pathway due to starvation of cells for essential cofactor tetrahydrofolate (not shown) by TMP treatment. Thymine and thymidine represent external metabolites transported from the media. Genes associated with pathways: 1 cdd; 2 - deoA; 3 - deoB; 4 - deoC; 5 - tdk; 6 - yjjG; 7 - tdk; 8 - nudl/ dut; 9 - thyA; 10 - tmk; 11 - ndk. Abbreviations: dCyt: deoxycytidine; dUrd.: deoxyuridine; Ura. - uracil; dR1P - deoxyribose-1-phosphate; dR5P: deoxyribose-5-phosphate; G3P/acet:: glyceraldehyde-3phophate/acetaldehyde; Thd - thymidine (external); Thy - thymine (external). of dR5P caused by utilization of dR1P by thymine to replenish thymidine for dTTP synthesis. In the absence of functional $\operatorname{deo} A$, cells are able to utilize all the thymidine in the medium for dTTP synthesis, since it cannot be catabolized to thymine. Furthermore, when $\operatorname{deo} C$ is mutated, not only is thymidine not catabolized, the accumulation of dR5P may also derepress $\operatorname{deo} A$ to allow the scavenging of thymine from the medium. This explains the refractory nature of the $\operatorname{deo} C$ and $d e o A$ mutants to TMP in LB. It is likely that once thymidine is exhausted from the medium, cells may continue on their bactericidal trajectory provided they sustain continued growth in the presence of other folate dependent metabolites, and provided TMP is effective in inhibiting DHFR. However, when the operon is completely derepressed due to the absence of deoR, the cells fail to repress the catabolism of thymidine and they may run out of thymidine quicker than wild-type strain in LB explaining the sensitive phenotype.

In minimal medium supplemented with amino acids and purine, cells cannot utilize exogenous thymine or thymidine like in LB. dTTP depletion during thymine starvation induces the ribonucleoside-diphosphate reductases, which increases flux through the dTTP biosynthetic pathway and causes an accumulation of dCTP and dUMP $[45,46]$. In M9TMPAdAA condition, we see an up-regulation of the $\operatorname{nrdAB}$, genes (log-ratio > 0.5) responsible for the reduction of pyrimidine ribonucleotides to dUTP, indicating that similar conditions may exist during this treatment. The excess accumulated dUTP can then get incorporated into DNA or can be degraded to dUMP and further to deoxyuridine and dR1P via the dUMP phosphatase YjjG [42,43,47]. During thymine starvation, excess ribose sugar is secreted into the medium, particularly in $d e o C^{-}$mutants [48]. In a $d e o A^{-}$mutant, the cells lack the ability to degrade deoxyuridine and this may lead to the increased accumulation of dUMP and dUTP in the cells, possibly due to the conversion of the accumulated deoxyuridine to dUMP via thymidine kinase [49].

Similarly, in deo $C^{-}$mutant, dUMP cannot be catabolized leading to dUTP accumulation. The slight difference in sensitivity in $d e o A$ and $d e o C$ to TMP (Figure $4 \mathrm{~B})$ could be attributed to the activity of uridine phosphorylase (Udp) which also degrades deoxyuridine at much lower rate than DeoA [50]. Finally, the deo $R^{-}$ mutant should be similar to the wild-type since in the wild-type, the deo operon is derepressed due to accumulation of dR5P, and the loss of viability in deoR is similar to that in the wild-type strain.

In the current study, we observed that the kinetics of killing by TMP was similar to that by thymine starvation: 1-2 hour lag is followed by a relatively rapid loss of viability. Moreover, induction of the SOS response in 
both conditions occurred in the first half of the lag stage, indicating that DNA becomes damaged long before the cells loose their ability to divide. The duration of the lag stage can in principle be determined by two factors: 1 the time it takes for dTTP to drop below a certain level to cause replication fork arrest; 2 - the time it takes for DNA damage to become irreversible. While the first factor can be postulated a priori; the second is derived from the observation that the loss of RecA or RecBC function shortens or eliminates the lag [41], suggesting that double-strand break repair pathway has a capacity to reverse some effects of the starvation. It is likely that the shortening of the lag in a $d e o R^{-}$mutant in the rich medium was due to faster depletion of the UTTP pool, and the phenotype of $d e o C^{-}$and $d e o A^{-}$mutants in the rich medium can be viewed as an extension of the lag stage due to the pool maintenance in the mutant cells effectively scavenging thymi(di)ne. When both dTTP and dUTP pools become fully exhausted, DNA damage becomes persistent and its processing by some repair enzymes makes the damage irreversible. Cells from this stage in the thymineless death pathway cannot be recovered and that accounts for a rapid decline in viability. In support of this view, mutants that can't process initial DNA damage, e.g., recF , loose viability at a much-reduced rate following the lag $[39,41]$.

It appears that the primary factor in establishing the rate of starvation-induced killing is a number of chromosomal replication events in a bacterial population. The higher the rate of initiation and the greater the number of growing replication forks per chromosome, the higher the probability of the irreversible chromosomal collapse [40]. In principle, if the dTTP pool is efficiently replenished with dUTP, that would prevent replication fork arrest (at least in the current replication cycle) and thus would reduce the probability of the subsequent chromosomal collapse. Such replenishment does not happen under conventional thymine starvation in thy A auxotrophs because of the activity of dUTPase, which efficiently hydrolyzes dUTP to dUMP and PPi [51] and because of the yjjG-deo pathway, which catabolizes excess dUMP and dU $[42,43,47]$. That is probably why the thymineless death triggered by thymine starvation in thymidylate auxotrophs is not affected by the activity of uracil- $\mathrm{N}$-glycosyase, the first enzyme in the uracil base excision pathway [41,52]: although uracil may be occasionally found in DNA from some mutant TLD cells, its post-replicative excision would not matter much since the chromosome would be already on its way toward collapse from the fork arrest, i.e., for uracil to be incorporated in a part of DNA, the replication fork must traverse that part of DNA in the template, incorporation of $U$ signifies exhaustion of dTTP and since dUTP are readily hydrolyzed, the fork that started incorporating U's is subject to an eminent arrest. As a result, the kinetics of the viability loss would be determined by the frequency of fork arrests and not by the frequency of other DNA lesions.

However, in the conditions that maybe prone to a slower exhaustion of the dTTP pool, due to indirect or limited inhibitory effect on the thymidylate synthase and/or significant increase of dUTP over dTTP, incorporation of uracil may become a factor in determining the outcome of dTTP starvation. For example, chromosomes that are fully replicated in the presence of sufficient dUTP may eventually collapse as a result of uracil excision repair, which could be initiated but not completed in the absence of dTTP or dUTP. That appears to be the case in yeast treated with the antifolate inhibitor aminopterin [53] and in animal cells treated with the antifolate drug methotrexate [54]. We argue that at least in $d e o C^{-}$and $d e o A^{-}$cultures treated with TMP, a fraction of cells can complete the ongoing rounds of DNA replication, using dUTP in combination with slowly decaying dTTP supply, and these chromosomes would collapse primarily because of uracil processing and not because of replication fork arrest. Consistent with that is the observation that the lag stage was not affected in the deo $C^{-}$and $d e o A^{-}$mutants; instead, the loss of viability was relatively accelerated in these mutants - pointing at an additional source(s) of irreversible DNA damage. It is possible that TMP treatment of E. coli, independent of the growth medium and similar to anti-folate treatments in higher organisms, results in dUTP levels sufficient to support DNA replication. Processing uracil out of such DNA with UNG would be detrimental to the cells. This assertion is supported in part by our observation that an ung mutant yielded in our screen 3 times as much biomass as an average strain (data not shown) and by observations from a chemical genomics screen where $d u t^{-}$and $u n g^{-}$mutants showed fitness defect, while $d c d^{-}$ showed fitness advantage in response to the TMP treatment [55]. Thus, it is likely that depending on the mechanism of thymine starvation (TMP versus direct thymidylate deficiency) and despite apparent similarities between them, different components of DNA metabolism may contribute to the starvation outcomes.

\section{Conclusion}

Treatment of E. coli bacteria with the antibiotic Trimethoprim results in regulatory responses that can be associated with the drug mechanism as well as treatment conditions. Depending on the treatment condition, the drug can have bacteriostatic or bactericidal effect. The DNA damage response can be used to discriminate between the bacterial killing, which is preceded by the damage response, and the bacteriostasis, during which the damage response does not develop. The drug 
induces DNA damage at the beginning of the characteristic lag stage of the treatment. Mutations in the deoxyribose nucleotide salvage pathway can affect duration of the lag as well as the rate of killing. The duration of the lag is likely determined by the capacity of the cells to buffer the effect of thymine starvation caused by the drug, e.g., through dTTP pools. The rate of killing, however, is determined by the distribution of drug sensitivities across a bacterial population. The sensitivity of individual cell in turn should be determined by its stage in the replication and division cycles. We speculate that Trimethoprim, by affecting replication and possibly division cycles, makes uracil incorporation into DNA an important source of the offending lesion in the druginduced thymine starvation.

\section{Additional material}

Additional file 1: Gene Sets. A list of gene sets used in the analysis and individual genes that make up sets. The file contains two excel sheets: "Gene Sets" enumerates all classified sets; "Gene Set membership" classifies genes into sets: 1 - a member, 0 - not a member.

Additional file 2: Analysis code. $R$ code used for the analysis of the data and tools for retrieving individual gene set scores and generating plots.

Additional file 3: Coefficients of a set score linear model on individual supplements. Set scores and set coefficients obtained from the linear model employed to assess the effects of individual supplements (as described in main text).

Additional file 4: Gene Sets associated with the lethality phenotype List of gene sets up-regulated in bacteriostatic or bactericidal conditions along with their linear model coefficients.

Additional file 5: Plots of gene set scores associated with the lethality phenotype. Boxplots identifying the set score differences between static and cidal conditions.

Additional file 6: Comparison of non-parametric (AUC) and parametric (linear model FDR) significant tests for sets. Scatter plot of AUC scores and False Discovery Rates (FDR) from the linear model indicating strong correlation between the two measures of association between set scores and cell phenotype.

Additional file 7: O.D. values of deo mutants after TMP treatment in M9 and LB media. A) LBTMP treatment. Increase in O.D. (600 nm) after $50 \mathrm{\mu g} / \mathrm{ml}$ TMP treatment of wild-type MG1655 strain (blue), deoA (red), deoC (green) and deoR (purple) knock-out mutants in LB medium. TMP was added to respective cultures grown from overnight inoculum to mid-log phase in LB medium at O.D. 0.37-0.42 (Time 0 hr). B) M9TMPAdAA treatment. Increase in O.D. (600 nm) after $25 \mu \mathrm{g} / \mathrm{ml}$ TMP treatment of wild-type MG1655 strain (blue), deoA (red), deoC (green) and deoR (purple) knock-out mutants in M9 medium. TMP was added to respective cultures grown from overnight inoculum to mid-log phase in M9 medium at O.D. 0.25-0.35 (Time $0 \mathrm{hr}$ ).

\section{Acknowledgements}

We thank Drs. Hirotada Mori for the gift of a knock-out library, Friedrich Srienc for financial support, Patrick Higgins for the gift of P1 phage. This work was supported in part by grant GM066098.

\section{Author details}

${ }^{1}$ Lewis-Sigler Institute for Integrative Genomics, Princeton University, 132 Carl C. Icahn Laboratory, Princeton University, Washington Road, Princeton NJ 08540, USA. ²Department of Biochemistry, Molecular Biology and Biophysics,
University of Minnesota, 1479 Gortner Ave, Saint Paul, MN 55108, USA. ${ }^{3}$ Biotechnology Institute, University of Minnesota, 1479 Gortner Ave, Saint Paul, MN 55108, USA. ${ }^{4}$ Metabolix Inc., 21 Erie Street, Cambridge, MA 02139, USA.

\section{Authors' contributions}

DS performed the genetic screen, analyzed the data and co-wrote the manuscript. ZZ performed the microarray experiments. AK conceived of the study and co-wrote the manuscript. All authors read and approved the final manuscript.

Received: 12 August 2011 Accepted: 28 November 2011

Published: 28 November 2011

\section{References}

1. Bushby S, Hitchings G: Trimethoprim, a sulphonamide potentiator. British journal of pharmacology and chemotherapy 1968, 33(1):72.

2. Burchall JJ, Hitchings $\mathrm{GH}$ : Inhibitor binding analysis of dihydrofolate reductases from various species. Molecular pharmacology 1965, 1(2):126.

3. Burchall JJ: Mechanism of action of trimethoprim-sulfamethoxazole. II. J Infect Dis 1973, 128(Suppl):437-441.

4. Amyes S, Towner K: Trimethoprim resistance; epidemiology and molecular aspects. Journal of medical microbiology 1990, 31(1):1-19.

5. Huovinen P: Trimethoprim resistance. Antimicrob Agents Chemother 1987, 31(10):1451-1456.

6. Huovinen P: Increases in rates of resistance to trimethoprim. Clin Infect Dis 1997, 24(Suppl 1):S63-66.

7. Murray BE, Alvarado T, Kim KH, Vorachit M, Jayanetra P, Levine MM, Prenzel I, Fling M, Elwell L, McCracken GH: Increasing resistance to trimethoprim-sulfamethoxazole among isolates of Escherichia coli in developing countries. The Journal of Infectious Diseases 1985, 152(6): 1107-1113.

8. Huovinen P, Sundström L, Swedberg G, Sköld O: Trimethoprim and sulfonamide resistance. Antimicrobial Agents and Chemotherapy 1995, 39(2):279.

9. Blakley RL: The biochemistry of folic acid and related pteridines. NorthHolland Publishing Co.; 1969.

10. Harvey R, Dev I: Regulation in the folate pathway of Escherichia coli. Advances in enzyme regulation 1975, 13:97-124.

11. Smith RJ, Midgley JE: The effect of trimethoprim on macromolecular synthesis in Escherichia coli. Biochem J 1973, 136(2):225-234.

12. Kwon YK, Higgins MB, Rabinowitz JD: Antifolate-induced depletion of intracellular glycine and purines inhibits thymineless death in E. coli. ACS Chem Biol 2010, 5(8):787-795.

13. Dale BA, Greenberg GR: Effect of the folic acid analogue, trimethoprim, on growth, macromolecular synthesis, and incorporation of exogenous thymine in Escherichia coli. J Bacteriol 1972, 110(3):905-916.

14. Miovic M, Pizer LI: Effect of trimethoprim on macromolecular synthesis in Escherichia coli. Journal of Bacteriology 1971, 106(3):856.

15. Amyes SG, Smith JT: Trimethoprim action and its analogy with thymine starvation. Antimicrobial Agents and Chemotherapy 1974, 5(2):169-178.

16. Then R, Angehrn P: Nature of the bactericidal action of sulfonamides and trimethoprim, alone and in combination. The Journal of Infectious Diseases 1973, 128:498-501.

17. Then R, Angehrn P: Sulphonamide-induced 'thymineless death' in Escherichia coli. Microbiology 1973, 76(2):255.

18. Sambrook J, Russell DW: Molecular cloning: a laboratory manual. Cold Spring Harbor, N.Y.: Cold Spring Harbor Laboratory Press; 32001.

19. Khodursky AB, Bernstein JA, Peter BJ, Rhodius V, Wendisch VF, Zimmer DP: Escherichia coli spotted double-strand DNA microarrays. Functional genomics Humana, Totowa 2003, 61-78.

20. Smyth G: Limma: linear models for microarray data. Bioinformatics and computational biology solutions using $R$ and Bioconductor 2005, 397-420.

21. Serres MH, Riley M: MultiFun, a multifunctional classification scheme for Escherichia coli K-12 gene products. Microbial \& comparative genomics 2000, 5(4):205-222.

22. Gama-Castro S, Salgado H, Peralta-Gil M, Santos-Zavaleta A, MuÒizRascado L, Solano-Lira H, Jimenez-Jacinto V, Weiss V, Garcla-Sotelo JS, LÛpez-Fuentes A: RegulonDB version 7.0: transcriptional regulation of Escherichia coli K-12 integrated within genetic sensory response units (Gensor Units). Nucleic Acids Research 2011, 39(suppl 1):D98. 
23. Keseler IM, Collado-Vides J, Santos-Zavaleta A, Peralta-Gil M, Gama-Castro S, MuÖiz-Rascado L, Bonavides-Martinez C, Paley S, Krummenacker M, Altman T: EcoCyc: a comprehensive database of Escherichia coli biology. Nucleic Acids Research 2011, 39(suppl 1):D583.

24. Tian L, Greenberg SA, Kong SW, Altschuler J, Kohane IS, Park PJ: Discovering statistically significant pathways in expression profiling studies. Proceedings of the National Academy of Sciences of the United States of America 2005, 102(38):13544.

25. Zare $H$, Sangurdekar D, Srivastava P, Kaveh M, Khodursky A: Reconstruction of Escherichia coli transcriptional regulatory networks via regulon-based associations. BMC Syst Biol 2009, 3:39.

26. Adler P, Peterson H, Agius P, Reimand J, Vilo J: Ranking Genes by Their Co expression to Subsets of Pathway Members. Annals of the New York Academy of Sciences 2009, 1158(1):1-13.

27. Sangurdekar DP, Srienc F, Khodursky AB: A classification based framework for quantitative description of large-scale microarray data. Genome Biology 2006, 7(4):R32.

28. Storey JD, Akey JM, Kruglyak L: Multiple locus linkage analysis of genomewide expression in yeast. PLoS Biology 2005, 3(8):1380.

29. Leek JT, Storey JD: Capturing heterogeneity in gene expression studies by surrogate variable analysis. PLOS Genet 2007, 3(9):1724-1735.

30. Storey JD: The positive false discovery rate: A Bayesian interpretation and the q-value. Annals of Statistics 2003, 2013-2035.

31. Tuszynski J: caTools: Tools: moving window statistics, GIF, Base64, ROC AUC, etc. $R$ package version 2008, 1.

32. Baba T, Ara T, Hasegawa M, Takai Y, Okumura Y, Baba M, Datsenko KA, Tomita M, Wanner BL, Mori H: Construction of Escherichia coli K-12 inframe, single-gene knockout mutants: the Keio collection. Molecular systems biology 2006, 2(1).

33. Datsenko KA, Wanner BL: One-step inactivation of chromosomal genes in Escherichia coli K-12 using PCR products. Proceedings of the National Academy of Sciences of the United States of America 2000, 97(12):6640.

34. Lennox E: Transduction of linked genetic characters of the host by bacteriophage P1. Virology 1955, 1(2):190-206.

35. Alikhanian S, Iljina TS, Kaliaeva ES, Kameneva SV, Sukhodolec V: A genetical study of thymineless mutants of E. coli K12. Genet Res 1966, 8(1):83-100.

36. O'Donovan GA: Thymidine metabolism in bacteria. DNA synthesis, present and future Plenum Publishing Corp, New York; 1977, 219-253.

37. Sangurdekar DP, Hamann BL, Smirnov D, Srienc F, Hanawalt PC, Khodursky AB: Thymineless death is associated with loss of essential genetic information from the replication origin. Mol Microbiol 2010, 75(6):1455-1467

38. Camara JE, Breier AM, Brendler T, Austin S, Cozzarelli NR, Crooke E: Hda inactivation of DnaA is the predominant mechanism preventing hyperinitiation of Escherichia coli DNA replication. EMBO Rep 2005, 6(8):736-741.

39. Fonville NC, Bates D, Hastings PJ, Hanawalt PC, Rosenberg SM: Role of RecA and the SOS response in thymineless death in Escherichia coli. PLoS Genet 2010, 6(3):e1000865.

40. Martin CM, Guzman EC: DNA replication initiation as a key element in thymineless death. DNA repair 2011, 10(1):94-101.

41. Kuong KJ, Kuzminov A: Stalled replication fork repair and misrepair during thymineless death in Escherichia coli. Genes Cells 2010, 15(6):619-634.

42. Ahmad S, Pritchard R: A regulatory mutant affecting the synthesis of enzymes involved in the catabolism of nucleosides in Escherichia coli. Molecular and General Genetics MGG 1971, 111(1):77-83.

43. Hammer Jespersen K, Munch Petersen A, Nygaard P, Schwartz M: Induction of enzymes involved in the catabolism of deoxyribonucleosides and ribonucleosides in Escherichia coli K 12. European Journal of Biochemistry 1971, 19(4):533-538.

44. Koch $A E$, Burchall JJ: Reversal of the antimicrobial activity of trimethoprim by thymidine in commercially prepared media. Applied and Environmental Microbiology 1971, 22(5):812.

45. Neuhard J, Thomassen E: Turnover of the deoxyribonucleoside triphosphates in Escherichia coli $15 \mathrm{~T}$ during thymine starvation. European Journal of Biochemistry 1971, 20(1):36-43.

46. Mollgaard $\mathrm{H}$, Neuhard J: Biosynthesis of deoxythymidine triphosphate. Metabolism of nucleotides, nucleosides, and nucleobases in microorganisms Academic Press, London, United Kingdom; 1983, 149-198.
47. Weiss B: YjjG, a dUMP phosphatase, is critical for thymine utilization by Escherichia coli K-12. Journal of Bacteriology 2006, JB. 01645-01606v01641.

48. Breitman T, Bradford R: The absence of deoxyriboaldolase activity in a thymineless mutant of Escherichia coli strain 15: a possible explanation for the low thymine requirement of some thymineless strains. Biochimica et biophysica acta 1967, 138(1):217.

49. Ives DH, Morse PA, Potter VR: Feedback inhibition of thymidine kinase by thymidine triphosphate. J Biol Chem 1963, 238:1467-1474.

50. Leer JC, Hammer Jespersen K, Schwartz M: Uridine phosphorylase from Escherichia coli. European Journal of Biochemistry 1977, 75(1):217-224.

51. Kornberg A, Baker TA: In DNA replication. Volume 5. WH Freeman New York; 1992.

52. Kunz BA, Glickman BW: Mechanism of mutation by thymine starvation in Escherichia coli: clues from mutagenic specificity. J Bacteriol 1985, 162(3):859-864.

53. Tinkelenberg BA, Hansbury MJ, Ladner RD: dUTPase and uracil-DNA glycosylase are central modulators of antifolate toxicity in Saccharomyces cerevisiae. Cancer Res 2002, 62(17):4909-4915.

54. Goulian M, Bleile B, Tseng BY: The effect of methotrexate on levels of dUTP in animal cells. J Biol Chem 1980, 255(22):10630-10637.

55. Nichols RJ, Sen S, Choo YJ, Beltrao P, Zietek M, Chaba R, Lee S, Kazmierczak KM, Lee KJ, Wong A, et al: Phenotypic landscape of a bacterial cell. Cell 2011, 144(1):143-156.

\section{doi:10.1186/1471-2164-12-583}

Cite this article as: Sangurdekar et al:: The association of DNA damage response and nucleotide level modulation with the antibacterial mechanism of the anti-folate drug Trimethoprim. BMC Genomics 2011 12:583.

\section{Submit your next manuscript to BioMed Central and take full advantage of:}

- Convenient online submission

- Thorough peer review

- No space constraints or color figure charges

- Immediate publication on acceptance

- Inclusion in PubMed, CAS, Scopus and Google Scholar

- Research which is freely available for redistribution 